\title{
EARTH AT NIGHT: AN IMAGE OF THE NIGHTTIME EARTH BASED ON CLOUD-FREE SATELLITE PHOTOGRAPHS
}

\author{
WOODRUFF T. SULLIVAN, III \\ Department of Astronomy FM-20, University of Washington, \\ Seattle, WA 98195, USA
}

\begin{abstract}
An image of the entire earth at nighttime is assembled for the first time. It consists of a mosaic of photographs, all taken at local midnight in the $400-1100 \mathrm{~nm}$ band, made by the Defense Meteorological Satellite Program over the period 1974-84. Photographs were selected for freedom from clouds, lack of moonlight, high sensitivity, and suitability to illustrate various temporal phenomena. The image primarily reveals activities of humankind such as urban street lighting, rangeland burning, slash-and-burn agriculture, natural gas burnoffs in oilfields, and squidding. Although light pollution in urban areas creates a striking map, at the same time it devastates astronomical observation and removes much of humankind from any familiarity with the night sky.
\end{abstract}

\section{INTRODUCTION}

Figure 1 is a new image of the earth, representing the first time that a mosaic of the entire earth at night has been assembled. With daytime images having resolutions of a few kilometers, only natural features are easily visible (Sagan and Wallace 1971), but the nighttime activities of humankind are readily traced in photographs from the US Air Force's Defense Meteorological Satellite Program (DMSP).

Much of the light leakage to space corresponds to street and building lights in urbanized regions, especially in Europe (Fig. 2), North America (Fig. 3), and eastern Asia. Also nicely etched are transportation features such as the TransSiberian railroad, the main railroad (Jing-Bao/Bao-Lan) through central China, the spoke pattern centered on the hub of Moscow, and Interstate Highway 5 along the western coast of the United States. The delimiting effects of geographical features such as the Nile River, the Sahara Desert, the Himalayas, and the Australian Outback are also apparent. Perhaps more surprising is how well certain political boundaries can be discerned. For example, in Fig. 2 one can easily see the effects of differing lighting policies in France vis-a-vis England or Belgium, or in East Germany vis-a-vis West Germany.

In the tropics, the major sources of light are controlled fires- the results of grassland burning, slash-and-burn agriculture, and clearing of forests (for further details see Sullivan 1989, Seiler and Crutzen 1980, and Grigg 1974). The number 
of these fires depends on season, but in the present image there may be as many as one million. They are prominent throughout the highlands of Southeast Asia, the sub-Saharan savannas, and East Africa. Other lights arise from huge burnoffs of natural gas associated with oil wells. Gas flares show clearly in Indonesia, the Tashkent region of the Soviet Union, Siberia, the Middle East, North and West Africa, and northwestern South America. The most peculiar source is in the Sea of Japan, where the large blotch of light emanates from a fishing fleet that displays over $100 \mathrm{MW}$ of lights on its boats in order to lure squid and saury to the surface.

Not illustrated here are two natural phenomena commonly detected by the satellites. These are aurorae, which cannot be properly shown on a Mercator projection, and lightning flashes, which overload the fast-scanning detector on the satellite and thus appear as small streaks.

\section{THE SATELLITE IMAGES}

Two DMSP satellites in sun-synchronous polar orbits provide global weather coverage, one always $800 \mathrm{~km}$ above the midnight-noon line and the other above the dawn-dusk line; all images in the present mosaic were taken at local midnight. Every 0.4 seconds each satellite scans a $3 \mathrm{~km}$ swath extending $3000 \mathrm{~km}$ in the east-west direction; resolution along the scan varies from $3 \mathrm{~km}$ at the nadir to $\sim 12 \mathrm{~km}$ at each end. The satellite measures several different wavelength bands, but all of the images used here are for the $400-1100 \mathrm{~nm}$ band,which is ideal for color temperatures corresponding to both fires and city lights. Sensitivity is $4 \times 10^{-7} \mathrm{~W} \mathrm{~m}^{-2}$ ster $^{-1}$, which in practice means that any source providing $\sim 50 \mathrm{~W}$ of upwardly-directed light can be detected; this can be compared with Landsat satellites, which at night are not even able to detect New York City!

Intensities measured with the DMSP satellites, however, are not well calibrated and their images have therefore had limited applications for scientific work. The dynamic range of the satellite's sensors at any time is only $\sim 100: 1$, and all lights on the final image presented here (after its several steps of processing) are full saturated.

\section{CAVEATS}

There are several aspects of this image that should be kept in mind. First, it comprises a mosaic of about forty individual photographs, most of which were copies of film strips found in the DMSP Archives at the National Snow \& Ice Data Center of the University of Colorado, Boulder. A few were taken from reports (Croft 1977, 1978) or from regional mosaics that had already been assembled. Because many of these photos had uncertain scales and various distortions, they were individually reduced to a common scale by digitizing them and using recognizable patterns of cities as fiduciary marks upon which corrections could be based. This was done such that the final overall image corresponds to a Mercator projection to about $5 \%$ accuracy. The individual photos were also taken with a variety of exposures and under varying moonlight, although photos with the least moonlight (and therefore highest sensitivity) were 
intensities in different regions are not at all on a common scale. Saturated images, in particular those of the gas flares, of course also lead to enlarged apparent sizes.

The photos in the mosaic were taken at various times and seasons over the period 1974-84; this affects in particular the occurrence of tropical fires, which are highly seasonal. Finally, portions of some photos were clouded out (e.g., southern China), and suitable photos were not available for other regions (e.g., a portion of southwestern Africa and all remote islands except New Zealand and the Hawaiians). The great dark regions of the various continents seen in this mosaic are, however, truly lacking in detectable light.

\section{CLOSING}

The image is replete with issues and potential investigations in geography, geophysics, meteorology, economics, anthropology, and environmental science. For example, why are the lighting practices of France and East Germany so different from those of Belgium and England? Why is Puerto Rico so much brighter than any other Caribbean island? How much land in the tropics is actually burnt every year in various regions? Contrast the luster of North America, Europe, and Japan, where one-quarter of the world's people use about three-quarters of the world's $10^{12}$ watts of electricity, with the darkness of Asia, Africa, and South America. (The per capita usages of electricity in the United States, Japan, China, and India are in the ratio of 75:30:2:1.)

Why is so much of the lighting intended for streets and buildings instead being wasted into space? Astronomers constantly battle the light pollution that damages their observations of faint stars and galaxies, but nevertheless increasingly find themselves limited to ever more remote and expensive sites.

Furthermore, hundreds of millions of people today are denied the beauty of a truly dark sky. No longer do they know the exquisite thrill of a meteor shooting across the sky, nor the humility induced by the splendor of two thousand stars wreathed by the Milky Way. We have instead wrapped Earth in a glowing fog and are cutting ourselves off from the universe. And it is ironically by looking back at the earth through these satellite images that we see this best of all.

\section{ACKNOWLEDGMENTS}

I thank Kerry Meyer for indispensable and imaginative help with the image processing and Greg Scharfen and Teri Gregory of the DMSP archives.

NOTE: "Earth at Night" is available as a $60 \times 90 \mathrm{~cm}$ poster, with a caption identifying almost 200 cities and other features, from Hansen Planetarium, 1098 South 200 West, Salt Lake City, Utah 84101, USA. As of 1990 , the cost is $\$ 6.00$ plus shipping ( $\$ 1.50$ in North America and $\$ 3.90$ to Europe).

Inquiries about individual photographs of particular regions that might be available should be sent to DMSP Archives, National Snow \& Ice Data Center, NOAA, Campus Box 449, University of Colorado, Boulder, CO 80309. 
For prints or slides of the entire image or of individual continents, write the International Dark-Sky Association, 3545 N. Stewart, Tucson, AZ 85716, USA.

\section{REFERENCES}

Croft, T.A., 1977, Nocturnal images of the earth from space. Rept. of Stanford Research Institute for the US Geological Survey, Reston, Virginia (order no. 68197).

Croft, T.A., 1978, Nighttime images of the earth from space. Scientific American, 239, 68-79 (July).

Grigg, D.B., 1974, The Agricultural Systems of the World: An Evolutionary Approach (Cambridge: Cambridge Univ. Press).

Sagan, C., and Wallace, D., 1971, A search for life on earth at 100 meter resolution. Icarus, 15, 515-54.

Seiler, W., and Crutzen, P.J., 1980, Estimates of gross and net fluxes of carbon between the biosphere and the atmosphere from biomass burning. Climatic Change, 2, 207-47.

Sullivan, W.T., III, 1989, A $10 \mathrm{~km}$ resolution image of the entire nighttime Earth based on cloud-free satellite photographs in the 400-1100 nm band. Intl. J. of Remote Sensing, 10, 1-5. 

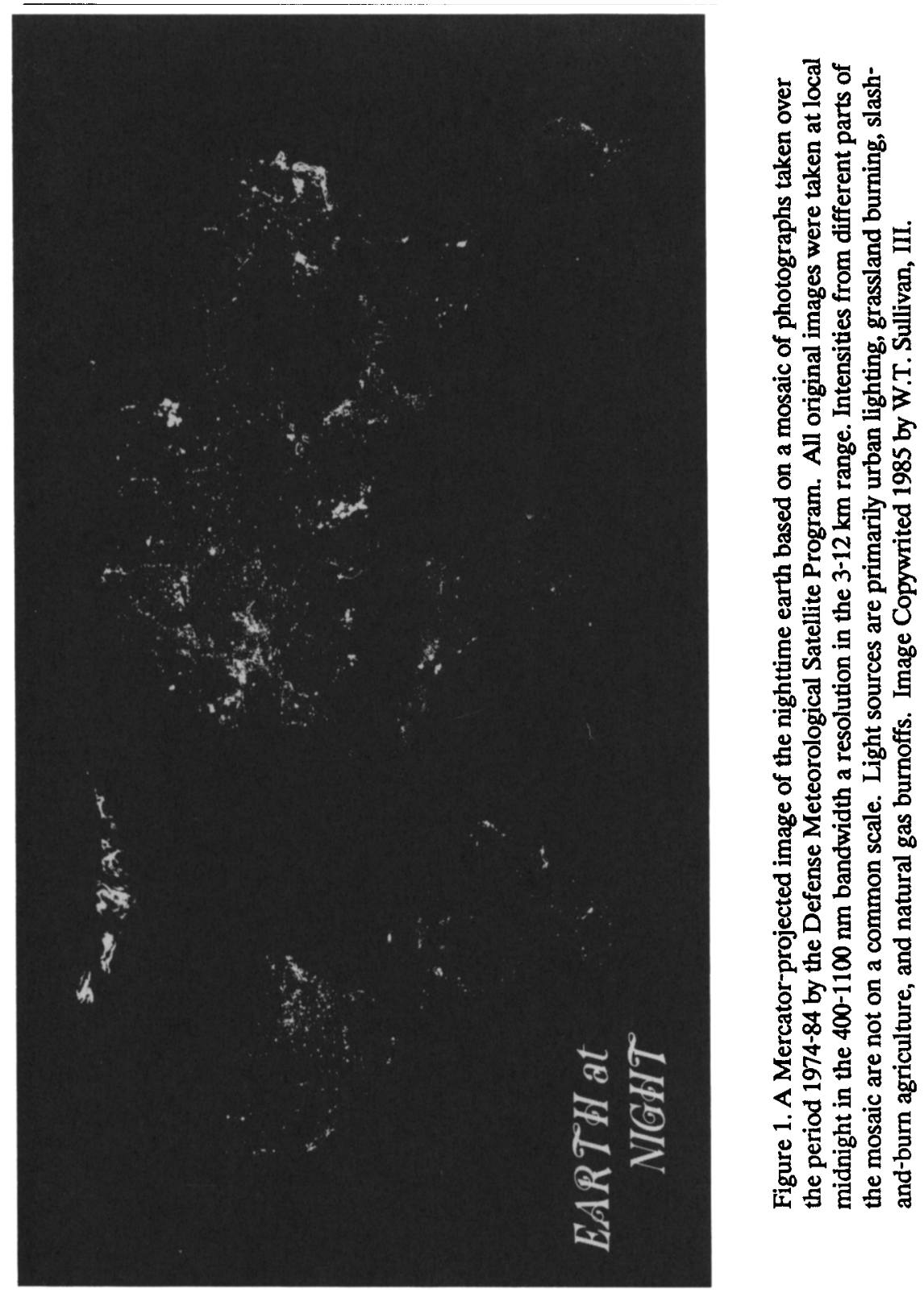


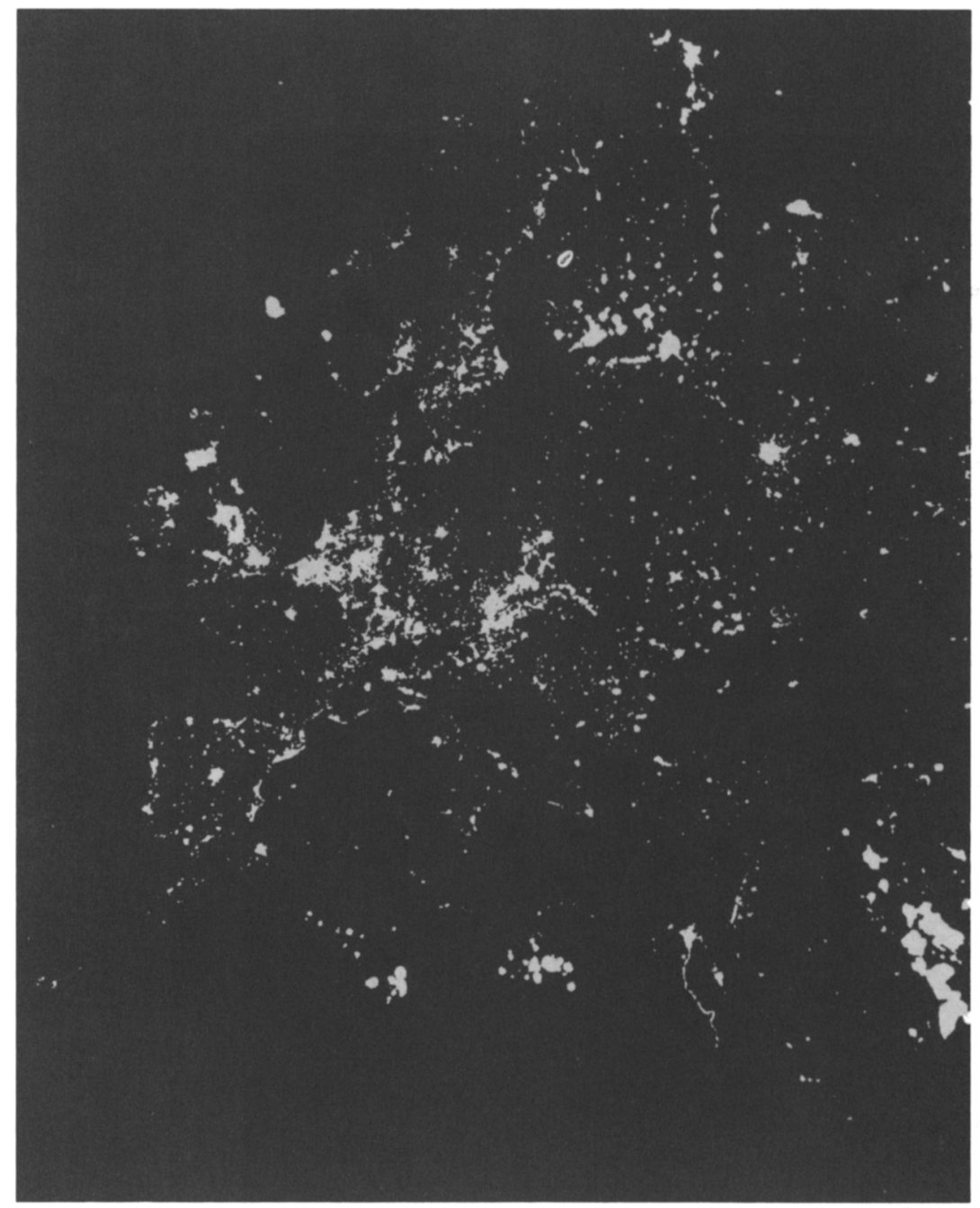

Figure 2. DMSP mosaic for North Africa, Europe, the Middle East, and central Asia. Note the Nile delta and valley, natural gas flares (in Algeria, Libya, the Persian Gulf region, and Siberia), and the visibility of political boundaries in Europe caused by differing lighting policies. 


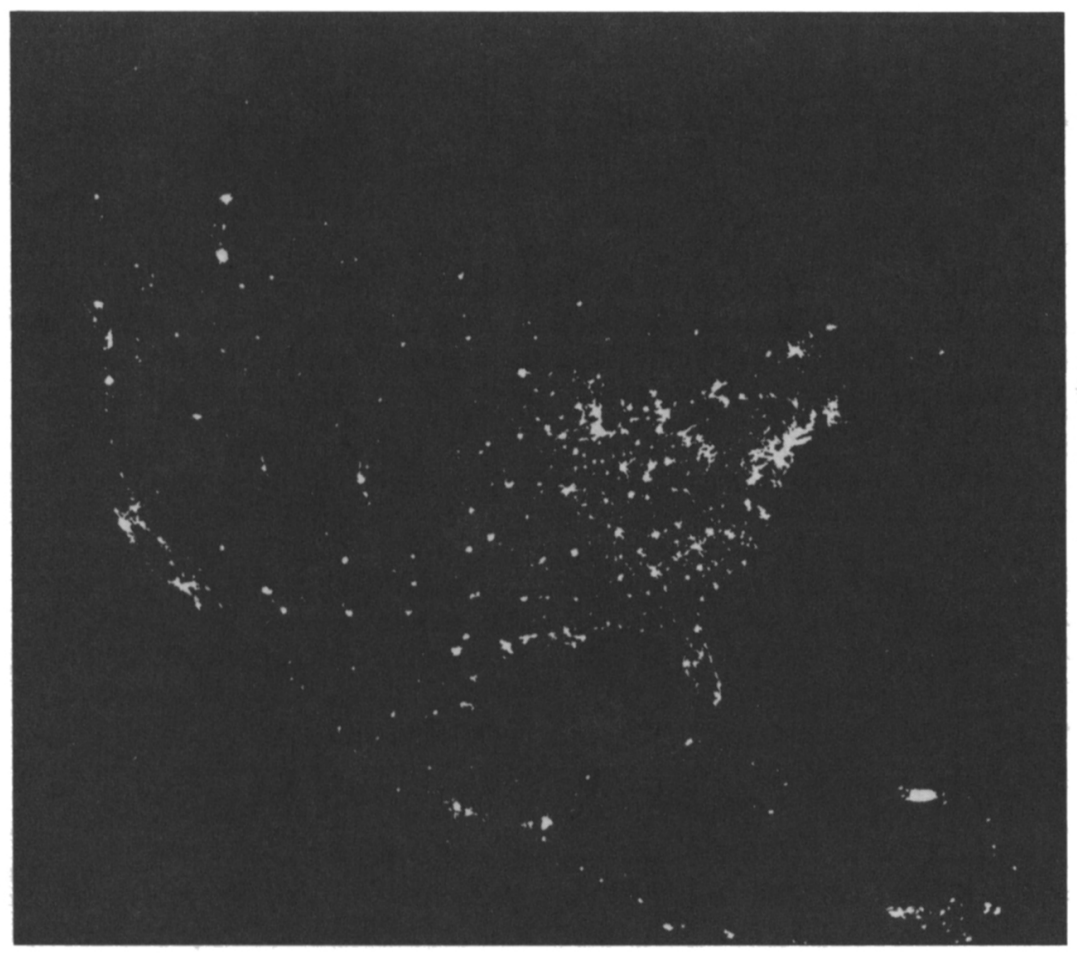

Figure 3. DMSP mosaic for North America; the image agrees remarkably well with a map of population density; on the original images almost any town of more than a few hundred inhabitants can be detected. 